\title{
The Effective Occupational Socialization of Specialists: a Model and the Reality
}

\author{
Aleksandra Vladimirovna Vaisburg ${ }^{1}$ \\ ${ }^{1}$ Tver State Technical University, Tver, Russia \\ Correspondence: Aleksandra Vladimirovna Vaisburg, Tver State Technical University, Nikitina - 22, Tver, \\ 170026, Russia. E-mail: lassie1@inbox.ru
}

Received: October 16, 2014 Accepted: November 5, 2014 Online Published: December 30, 2014

doi:10.5539/ass.v11n3p344

URL: http://dx.doi.org/10.5539/ass.v11n3p344

\begin{abstract}
This article analyses the theories of the process of the specialists' occupational socialization: dispositional and role theories, microsociological approaches (phenomenological and etnometodological). Teaching, psychological and sociological approaches have been analysed. On the basis of this analysis, the author has developed an integrated model of the specialists' occupational socialization, in which: the interpretation of the occupational socialization concept has been given, the basic elements, stages, levels, patterns and factors affecting this process have been spelt out. The main features of the specialists' occupational socialization have been also considered in stages.
\end{abstract}

Keywords: occupational socialization, specialist, model, features, school, university, employer, employment

\section{Introduction}

Dynamism of the modern social life, extremely complex and contradictory processes of reforming the Russian society determine the increasing importance of knowledge in many problems solving. The nature, content and features of the specialist's activity develop a special type of person who is the result of a complex and complicated process of occupational socialization, during which the certain values and behaviour patterns of the occupation are adopted. The solution of various socially important problems to a large extent depends on the level of the specialists' competence, which determines their knowledge, abilities and skills. However, nowadays the process of occupational socialization is carried out ambiguously and faces the certain problems.

The features of training the modern highly-qualified specialists are to a large extent determined by the current trends in the science itself, the education and the labour market.

The need for studying the issues of the occupational socialization is due to the fact that, firstly, the complex and contradictory processes are carried out in the modern science: the main paradigms are revised, the applied and academic fields have been increasingly differentiated, "alternating generations" of the specialists themselves could be seen, their public image have been changed.

Secondly, due to the introduction of the Bologna process and the shift towards the double-level training system the system of the higher vocational education has been transformed (in the form of the bachelor's and master's degrees). The Introduction of competency approach is designed to increase the level of the practical training and, thus, the graduates' competitiveness. The specialists' training has been increased due to the growth in the faculties and departments at the public and private universities. All this poses the new requirements for the academic stage of the specialists' occupational socialization.

The studies of occupational socialization are interdisciplinary in nature, as they affect the issues of education, psychology, management, philosophy, sociology, and this question has been still open-ended due to the insufficient development of this subject.

\section{Methods}

The principles of the dispositional and role theories have been used as the basic approach. The nature of the investigated issue has determined the integration of the major theoretical approaches to the analysis of occupational socialization (the specific historical, system, symbolic interactionism, phenomenological, structural and etnometodological approaches). The works by Weber M., Bourdieu P., Cooley C., Mead G., Linton R., 
Parsons T., Garfinkel H., Yadov V. A have been used. The modern theoretical researches on the issues of occupational socialization by the modern Russian sociologists: Batygin G. S., Zborowski G. E., Osipov G. V., Radaev V. V., Ryvkina R. V., Shcherbina V. V. et al. have been integrated into the methodological framework.

The methods of the theoretical level have been used at all the research stages and included: the theoretical analysis of the philosophical, sociological, educational, psychological and management literature.

\section{Results}

From the second half of the twentieth century the concept of the "occupational socialization" has been actively studied in the modern sense by the following scientists: Averyanov L.Y. (Averyanov, 2008), Golofast V., Ivanov O. N. (Golofast and Ivanov, 1972), Andreeva G. M. (Andreeva, 2006), Polishuk V. N. (Polishuk, 2013), Stenina T. L. (Stenina, 2014) etc.

Studying the forms, constituent elements, agents and institutions of occupational socialization is represented in the works by Morozova A. V. (Morozova, 2004), Valeyeva A. V. (Valeyeva, 2007), Kablinova Y. V. (Kablinova, 2006), Balashov V. N. (Balashov, 2002), Probst L. M. (Probst, 2004), Ivushkina V. O. (Ivushkina, 2012), Sadirin V. V. (Sadirin, 2013) et al.

Studying the factors, stages and levels of the occupational socialization is reflected in the works by Kuchmieva S. I. (Kuchmieva, 2007), Makarova S. N. (Makarova, 2007), Oparina O. D. (Oparina, 2008), Gross A. B. (Gross, 2004), Shatalov N. I. and Gemanov Y. N. (Shatalov, Gemanov, 2013), Kazandayev I. A. (Kazandayev, 2014), Yeriomina O. C. (Yeriomina, 2014), etc.

Under the analysed theories, the author has developed his own complex theory, which gives the interpretation of the occupational socialization concept and spells out the basic elements, stages, levels, patterns and factors affecting this process.

The methods of the theoretical level have been used at all the research stages and included: the theoretical analysis of the philosophical, sociological, educational, psychological and management literature. The methods of abstraction, analysis and synthesis, idealization, induction, the method of ascension from the abstract to specific objects have been also used.

It should be said, that the "occupational socialization" term is relatively new: it occurred in the scientific literature in the twentieth century and now it has been more widely used. The occupational socialization theory was initially considered in the context of various general theoretical compositions: the continental and Anglo-Saxon models (Abramov, 2005); dispositional theory (Weber, 1990; Bourdieu, 2005; Yadov, 1999); role theory (Cooley, 2007; Mead, 2007; Parsons, 2000; mikrosociological approaches - the phenomenological and etnometodological ones (Garfinkel, 2006). From the second half of the twentieth century the concept of the "occupational socialization" has been actively studied in the modern sense further to the stated theories.

While developing the dispositional theory the ideas of Weber M. (Weber, 1990), Bourdieu P. (Bourdieu, 2005), Yadov V. A. (Yadov, 1999) and some Russian scientists were used.

According to the dispositional theory, occupational socialization is a multifaceted, gradual process, which is socially determined by developing the social and occupational orientations of a person. This process defines the occupational choice according to its dispositions (the dispositions to the certain actions and evaluations), which creates a motivational basis for acquiring knowledge, abilities and skills, and contributes to its establishing as a subject of a particular type of the professional activity.

The role personal theory was developed by such foreign sociologists, as Cooley C., Mead G., Linton R. and Parsons T. Nowadays the development of the role theory is reflected in the works by Averyanov L. Y., Golofast V. B., Zinchenko G. P., Ivanova O. I., Lenshin V. P., Paireli S. V., Perinskaya N. A.

In this approach occupational socialization is understood as a process of learning the role, role attitudes and norms, corresponding to a certain social and occupational status, by a person and establishing the competence in implementing the expectations associated with playing a particular social role (Lenshin, 2008). In this case, the proposed role, the system of certain expectations and the role played by a person coincide only upon the existence of the homogeneous social groups and the equality of the group members' statuses. In the role personal theory the occupational socialization agents act as the social control agents. The efficiency of the occupational socialization depends on the successful transfer of the occupational and cultural experience by the main agents and institutions. In this theory, the personal dispositions are interpreted as interferences for the successful socialization. 
The theorists of the symbolic interactionism in the foreign sociology consider occupational socialization as a process of learning the system of the social roles by an individual, which is carried out in the primary group by "adopting the role of the other". Cooley C. (Cooley, 2007), the author of the "looking-glass self" and small group theories, believed, that the individual "Self" finds the social quality during the interaction between the individual and group agents. The main rationale of Mead's G (Mead, 2007) approach is the fact that individuals respond to other individuals and the environment, depending on the values and characters, which they give their surrounding the individual perceives and evaluates himself in accordance with the estimates of the others.

The ideas of structural functionalist Parsons T. served as the basis for developing the role theory of occupational socialization. According to his ideas occupational socialization could be seen as an interaction, in which the universal occupational values are learned, and at the same time the ideal type of the social occupational group is developed in the context of the modern society (Parsons, 1998).

In the context of the role theory occupational socialization is seen as a duel process. On the one hand, drawing on the ideas of Parsons T., Averyanov L.Y. interprets occupational socialization as the way of internalising the social norms, which are inherent in the certain occupational environment. This process is carried out due to learning the social and occupational norms, standards and values, occupational experience by the individual and on its basis developing the inner attitudes as the elements of the specialist's personal structure. Occupational socialization - is a complex, ongoing process of "designing" the person, in which the optimal behavioural decision and the permanent occupational development are selected. Internalization leads to the development of intellectual socialization, as a person does not only reproduce the past knowledge, albeit in a highly professional manner, but also produces a fundamentally different, new knowledge, new ideas, allowing the public to take to a new stage of the social development (Averyanov, 2008).

On the other hand, Andreyeva G. M., Yermakova T. M., Lvova O. N., Safin V. F., Spiridonova G. T. indicate, that occupational socialization is a self-identity, realization of the person's potential, the degree of awareness of its subjective and objective role in the interaction with the occupational environment and reproduction of the occpational culture (Spiridonova, 1996).

Thus, occupational socialization is not only the objective, embodying the patterns of the social and cultural education of a man as a person, but also the subjective "self-driven" process. His movement is carried out on the basis of subjective attitudes, actions to change them and to meet the needs of the particular people. Safin V.F. (Safin, 1985) argues that the final of occupational socialization is the labour activity in which a person not only achieves wealth, but also asserts himself as a creator and establishes the human relationships.

In the role paradigm of occupational socialization it is also possible to examine the process of occupational socialization of the person, based on the adaptation theory, proposed by Merton R. and analyzed by Belyayeva L. A., Valeyeva A. V. (Valeyeva, 2007). This is due to the fact, that the adaptive personal abilities are crucial in this process. Occupational socialization serves as a selection of individuals with a high level of adaptability, but there is no guarantee that they have a high level of occupational competence.

Among the trends of the foreign sociology of the second half of the XX century, influenced the study of the occupational socialization phenomenon, the microsociological approaches should be drawn up.

In the context of the phenomenological trend the professional institutions - are the result of many interactions between the representatives of a particular occupation, officials and citizens, which affect the process of occupational socialization. Averyanov L.Y. sees occupational socialization as a process of developing the occupational space and an active search for his place in it, which is carried out within the limits and on the basis of some physical structure, through time and is implemented in the space due to the permanent occupational interaction. As a result of this socialization fundamentally new knowledge is acquired (Averyanov, 2008).

In the works by the representatives of the etnometodological approach (Garfinkel H.), considerable attention was paid to the study of verbal interaction between the participants of a professional activity and the role of agents in the process of occupational socialization.

Occupational socialization of a person is also considered in terms of the educational, psychological and sociological approaches.

In terms of the educational approach the concept of occupationsl socialization is used to "note the educatedly regulated interaction of the processes of social and occupational development during the shift from one stage to another in terms of training in vocational education institutions" (Balyayeva, 1994).

Psychological and sociological analysis of occupational socialization reveals the following approaches: 
1. Differential and psychological approach examines the occupational socialization as the process of forming the individual style of life, a part of which is the professional activity. Occupational socialization - it is human activity, which has any content depending on the stage of its development as the labour subject, which is heterogeneous and depends on various factors, stages and phases of the human development.

2. Social and psychological approach analyzes the occupational socialization as a gradual decision-making process, because of which it is possible to combine the preferences of the person himself and the needs of society as a result of the labour division. According to Kon I.S., in a certain life span of the selected path occupational socialization achieves, on the one hand, the balance between the given objective possibilities, which outline the potential scope of the human activities (social order of society), and, on the other hand - claims, abilities, knowledge and skills of the individual, using which he implements his possibilities, which are inherent in his life situation and his own nature (Kon, 1984).

3. Sociological approach considers the occupational socialization as a series of tasks set by society for a person. Here the concept of occupational socialization is used in two senses. In a broad sense, it is a process of developing the adaptation and integrative features of the person within that component of the general socialization process, which creates the potential for horizontal and vertical mobility in the field of labour relations throughout the person's life. In the strict sense, it could be considered within a particular social and occupational group and have a "strict" occupational orientation.

According to the author's integrated approach, occupational socialization - is a social and psychological adaptation and integration process, in which on the basis of existing inner orientation of the individual, the development of certain personal resources, under the influence of certain agents and institutions learning the occupational role attitudes, norms, knowledge, behaviour patterns and its subsequent life reproduction in a particular professional activity are carried out (Figure 1).

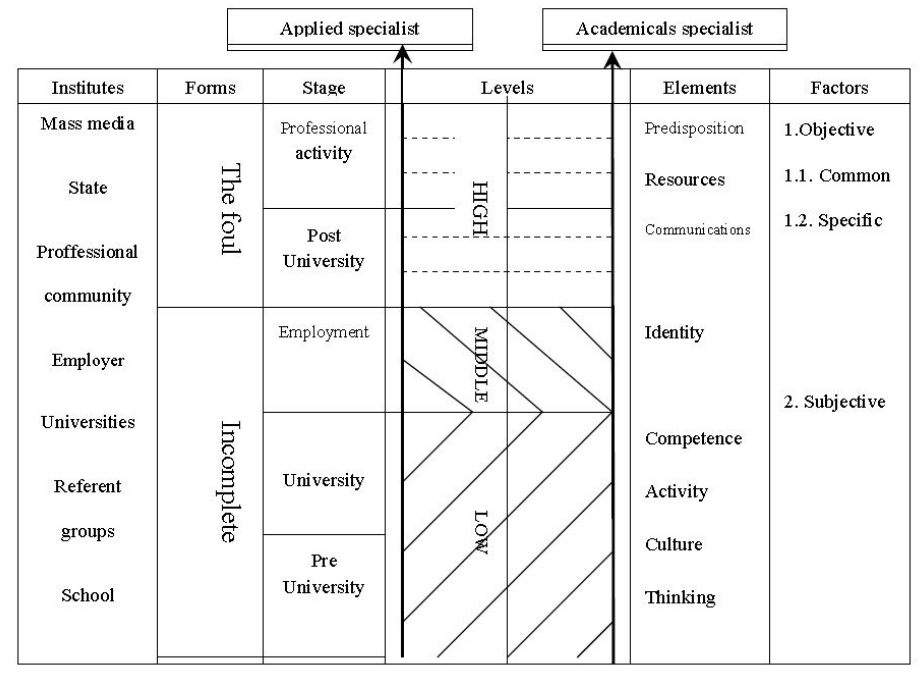

Figure 1. Model of professional socialization of a specialist

Occupational socialization includes the following elements:

1. occupational disposition (a disposition, a desire to become an expert in his field);

2. occupational resources (level of training in the required sciences, etc.);

3. professional activity (implementation of the basic functions of a specialist, which depend on the played occupational role);

4. occupational communications (occupational communication);

5. occupational identity (the degree of identification with the occupational group);

6. occupational awareness (all knowledge of the occupation);

7. occupational competence (knowledge of rights and duties within the occupation);

8. professional activity (involvement in the occupational interaction);

9. occupational culture (a set of norms and values governing professional occupational self-identity of specialists);

10. occupational thinking (identification of the individual himself with certain values and norms of the occupational group). 
All of these elements of the occupational socialization process are formed and developed at certain stages of the process. The author identifies the following classification of the stages of occupational socialization:

1. the pre-university one (schooling, career choice);

2. the university one(higher education - bachelor's and master's degrees, specialty);

3. the post-university one (post-graduate studies and doctoral studies in the specialty);

4. employment (choice of one of the occupational roles: the academic or applied one);

5. professional activities and improvement of competencies (occupational mobility and skill development through internship, courses, seminars, conferences, etc.).

As the specialist passes through these stages, he could increase the level of his occupational socialization. The author identifies the low, medium and high levels of occupational socialization. The low one is usually achieved by passing the pre-university and university stages of occupational socialization. It includes the specialists, who have got the initial idea of the occupation and a degree in the specialty, but they do not want to engage in this professional activity, they are not going to obtain employment and to work within their specialty.

The medium level is developed while passing through the pre-university, university and employment stages. The specialists, who have reached this level of occupational socialization, are carriers of the occupation, they are engaged in the professional activity, self-identify themselves with a particular occupational group, but they do not do anything to further develop their skills and they are slightly associated with the occupational community.

A high level of occupational socialization is achieved by passing through all the stages (pre-university, university, post-graduate, employment, professional activity and improvement of occupational knowledge). This level of occupational socialization is primarily reached by a small proportion of specialists. They have a strong intrinsic motivation to engage in this professional activity, occupational self, the individual style of work, achieve a high level of occupational mobility in career (due to improvement of their skills by postgraduate and doctoral studies), have strong ties to the occupational community, constantly improve and enhance their skills in internships, conferences, seminars, etc.

Occupational socialization, depending on passing through the specific stages and levels by a specialist could take the following forms: the partial and full ones. Partial occupational socialization means, that from the entire required scope of knowledge and occupational culture a person has learned only one part of it. The partial socialization sometimes results in such specialist's state, when he could be out of the occupational community.

Full occupational socialization is characterized by learning the entire scope of knowledge and culture of an occupational group, in this case, each specialist acquires the scope, which is required for playing his occupational role and problem solving. This is absolute compliance with the occupational group requirements and the successful performance of the occupational functions.

All these stages and levels of occupational socialization are influenced the objective and subjective factors. The objective ones include the general and specific factors. The general ones include: the social and demographic, political, social and psychological, spiritual and moral factors. Among the specific factors the following ones are identified: availability and quality of vocational education; capacity of the local labour market for these professionals and demand for such personnel; social and occupational mobility; generational and political membership of a specialist (Sokolov, 2009); the nature of the professional activity of the person himself (teaching, academic or commercial orientation) (Tartakovskaya 2010); the region of residence; the nature of social networks, which include any professional (relations with customers, authorities, leading occupational societies in Russia and abroad, participation in discussions, congresses and conferences); the public opinion; prestige and profitability of the occupation. The subjective (internal) factors of the specialists' occupational socialization are their social and demographic status, personal motivation, as well as intellectual capital (personal resources) (Panchenko, 2005). Among the factors of personal motivation the following ones could be: motivation for entering the university, the motivation for the learning activity and motivation for the occupational choice of a person. In turn, they include the following groups of motifs: the social, physical, prosocial, infantile, based on the interest in the occupation, teaching and cognitive, as well as development motifs.

It should be noted, that some conflicting interaction between the stages, levels and forms of occupational socialization could be seen. This is due to the influence of these factors, as well as the fact, that the stated levels and forms of occupational socialization are not always characterized by the presence of vocational education, occupation, etc., as there are enough examples of highly occupationally socialized specialists, who do not meet these requirements. This process could have intervals (eg, military service for men, maternity leave for women, etc.). In general, it is quite difficult to measure the level of the occupational socialization of a particular specialist, 
so in addition to the above indicators such criteria, as the following ones, should be also taken into account: a number of monographs and articles, participation in conferences, the presence of honorary titles, position, a number of studies, won grants, trained PhDs, etc.

The main institutions and agents of occupational socialization are the following ones: the state, education institutions (school, university), the occupational community, employers, the employment services, the mass media (the general and specialized ones), reference groups (a family). At various stages of occupational socialization any agents and institutions come to the forefront, but there are also those, which have a significant impact throughout the entire process.

Social institutions are the main agents of the occupational socialization of a person. Their importance for occupational socialization is very large, since the spontaneous behaviour of an individual is turned into the simulated, predictable and adjustable one by them. As a result, the social and occupational roles, norms and values are learned (Probst, 2004).

Occupational socialization integrates the interaction between many social institutions: the economic, social and cultural, political, scientific, educational and other ones. Each social institution has a socializing effect on the process of occupational development and performs the function of normalization, regulation and control of the occupational relationship:

- the social and cultural ones preserve and reproduce the social, occupational values, ensure the involvement of an individual in a specific occupational subculture;

- the economic ones act as a material reward and punishment for individuals;

- the political ones establish the loyalty of the current political system to a particular professional activity;

- the organizational and managerial ones provide an efficient, rational, as well as functional and role individual's behaviour in a formal organization (occupational rights and duties, occupational roles, responsibility, as set forth in charters, codes, and job descriptions);

- the approval ones establish the legal rules governing the professional activity;

- the orienting ones establish the occupational behaviour, determine the corporate moral and ethical occupational spirit;

- the ritual and symbolic ones regulate the specific occupational communication standards (rituals, ceremonies).

However, at different stages and for different target groups the particular social institutions come to the forefront during the occupational socialization.

As the specialist passes through the certain stages and levels during occupational socialization, he chooses for himself and plays one of the chosen occupational roles, although in some cases playing these roles could be mixed.

Drawing on the classification by Zaslavskaya T.I., the author identifies the roles of academic and applied specialist (Zaslavskaya, 1991), each of those has different features. Closer relationship with the professional academic community, high scientific activity, earning extra money by researches and grants, occasional skill development, preparation of scientific papers are typical for the academic specialist. The work on a variety of commercial orders, care about his prestige and image, active interaction with such agents, as the authorities, organizations, customers, specialty in the field of organizing and executing the researches with the further deepening of occupational socialization in line with the specific work performed are typical for the occupational socialization of the applied specialist.

\section{Discussion}

According to the model of this process developed by the author the features of occupational socialization in modern Russia (the main stages, levels, forms, institutions, elements, roles, factors) will be further considered.

The stage of the professional identity of future specialists in modern Russia is characterized by underdeveloping the system of occupational guidance for pupils, a lack of specialized classes and the mass media attention to the process of occupational development of the upper-form pupils. At this stage of occupational socialization the key role is played by such objective factors, as region of residence, the prestige and profitability of the occupation, and the subjective factors include - the social and demographic status, personal motivation and the intellectual capital.

At the stage of professional identity the following features of occupational socialization could be seen: only a small proportion of pupils have evident occupational preferences; most of them have no clear personal motives for entering and understanding of the specialty. 
At the university stage the specialists' occupational socialization is determined by the fact that nowadays a lot has been done for developing the education in Russia. It has gained the public recognition and institutionalization, as well as turned into a leading institution of occupational socialization. The issues of the modern education have a significant influence on the process of the specialists' occupational socialization and determine its features at the university stage. The following ones should be drawn up among them: a low level of the occupational and professional identity awareness; low social activity, reluctance to participate in seminars and conferences,a lack of interest in occupational development and papers; rather tenuous relationship with the professional community could be seen by most students in their first years at college (Smirnova, 2008).

The latest studies allow identifying some more features of occupational socialization at the university stage: at the stage of studying at the university the predominance of theoretical training and an acute shortage of skills (Toshchenko, 2008); the absence of the sufficient level of knowledge in the subjects required for the occupation; students' employment during their training.

At this stage, such objective factors, as the region of residence, availability and quality of the vocational education, as well as the subjective factors - the social and demographic status, personal motivation and the intellectual capital of a student have the greatest influence.

By the main body of graduates such elements of this process as the following ones are insufficiently developed: professional activity, resources and communications, professional identity, awareness and competence, professional activity, culture and the way of thinking.

All these features of the university stage do not allow the majority of the modern Russian specialists to reach even the medium level and the full form of occupational socialization.

Nowadays at the post-graduate stage of occupational socialization there are ample opportunities for undertaking further training in graduate and doctoral studies.

The features of the postgraduate stage of the occupational socialization of most specialists are, as follows: weak motivation, activity and commitment to train in graduate and doctoral studies; formal training in graduate studies (especially in men); combining training and employment; at the postgraduate stage the inflow of the specialists from the other associated sciences, which start to socialize occupationally in line with the occupation from this stage in particular. These features have to a certain extent the negative impact on increasing the professional level and achieving fuller form of occupational socialization.

At the stage of employment and professional activity a lot of changes, as compared with the Soviet period could be seen in modern Russia (Gottlieb, 2008).

The current situation in the labour market, the existing problems while getting a job and during the professional activity determines the features of the specialists' occupational socialization at this stage.

Thus, the main institutions, which have an impact on the stage of employment and professional activity in contemporary Russia are the employers, the state and the professional community.

The features, which describe the university stage of the specialists' occupational socialization remain to a large extent at the stage of employment and professional activity. At the same time, the specific features, which are typical for this stage only, occur: the low level of occupational mobility; commercialization of occupational values; negligence of the professional code; rare participation in the events intended to improve one's own occupational level (vocational courses, internships, etc.); weak commitment to publishing the results of one's own researches in periodicals; low motivation for work; absence of the new breakthrough ideas. Planning for the future professional activity often takes place not only in the context of the occupation obtained.

The process of the specialists' occupational socialization in modern Russia has also a great influence on such factor, as the place of residence. The experts note, that in large cities a relatively high level of vocational training, their demand in the labour market and the ample employment opportunities take place. Many specialists, who have graduated from the regional universities, seek employment in large cities.

\section{Conclusion}

However, according to the author, the process of occupational socialization, which is the basis for developing highly qualified professionals, is carried out inadequately nowadays, as many agents of occupational socialization have partial socializing influence. Accordingly, the society should be interested in the development of the targeted programs intended to change the current situation, which contribute to overcoming the barriers, impeding the process of the effective occupational socialization. 
Under the conducted theoretical analysis, the author has developed his own model of the specialists' occupational socialization. It includes an interpretation of the occupational socialization concept, the constituent elements, levels, forms, stages, mechanisms, main institutions, as well as the factors, which determine it. This model could be used by the social structures, employers, the administration of education institutions and professors in order to improve the system of the vocational guidance, training and retraining of specialists in the higher education institutions, solving the problems of young specialists.

\section{References}

Abramov, R. N. (2005). The Occupational Complex in the Social Structure of the Society (According to the Works by Parsons T.). Sociological Research, 1, 54-67.

Andreyeva, I. (2006, April 13). The Concept of Occupation. Portal of Andreyeva I. Retrieved April 13, 2006 , from http://www.irina-andreeva.ru/content/view/32/55/

Averyanov, L. Y. (2008, November 3). Looking for One's Own Ideas. New Digital Library Portal. Retrieved November 3, 2008, from http://www.read.newlibrary.ru/read/averjanov_1_ja_v_poiskah_svoei_idei.html/

Averyanov, L. Y. (2008, September 23). Socialization Threshold. Portal of the Russian Web University for Humanities. Retrieved 23.09.2008 from http://www.i-u.ru/biblio/archive/aver_porog/poisk5_12.aspx/.

Balashov, V. N. (2002). The Occupational Socialization of the Aviation Flying Personnel of the Russian Federation Armed Forces (PhD Thesis). Monino.

Bourdieu, P. (2005). The Power of Law: the Essentials of the Legal Field Sociology. The Social Space: Fields and Practices. St. Petersburg: Aletheia.

Concise Dictionary for the Vocational Education. (1994). St. Petersburg: Bochum.

Cooley, C. H. (2007). The Social Self. M.: Directmedia Publishing.

Eremina, O. C. (2014). Features of professional development of young experts//Materials of regional scientifically-practical Internet conference «Actual problems of socialisation of the person of students in the conditions of realization of the federal state educational standard » (from 27.03.2014г. to 28.04.2014) // http://www.tcek.ru/2014-04-01-05-12-57/869-2014-04-18-09-49-28.html

Garfinkel, H. (2006). Studies in Ethnomethodology. St. Petersburg: Piter Publishers.

Golofast, V. B., \& Ivanov, O. N. (1972). The Occupational Socialization Process and the Features of Developing a Young Teacher. The Sociological Problems of a Family and Young People, L.: Nauka Publishers.

Gottlieb, A. S. (2008). Structuring the Qualitative Research Practices as the Methodological Issue. Proceedings of the III All-Russian Sociological Congress, M.: The RAS Institute of Sociology, the Russian Society of Sociologists.

Gross, A. B. (2004). Occupational Socialization of a Student in Today's Russia. Educational Innovations, 4, 24-33.

Ivushkina,V. O. (2012). Professional socialization of youth (p. 31). The author's abstract on competition of a scientific degree of the candidate of sociological sciences.

Kablinova, Y. V. (2006). The Motivational Structure of the Youth's occupational Socialization. Proceeding of the Russian State Social University, 4(52), 67. Moscow

Kazandayev, I. A. (2014). Professional socialization of students as a problem of educational process // Materials of regional scientifically-practical Internet conference «Actual problems of socialization of the person of students in the conditions of realization of the federal state educational standard» (from 27.03.2014 to 28.04.2014.). Retrieved from http://www.tcek.ru/2014-04-01-05-12-57/841-2014-04-04-05-41-57.html

Kon, I. S. (1984). In Search of Oneself. Personality and Its Identity. M.: State Publishing House of Political Literature.

Kuchmieva, S. I. (2007). The Motivational factors of the Students' Occupational Socialization during Their Study at the University (PhD Thesis). Volgograd.

Lenshin, V. P. (2008). Socialization as an Integral Part of the Stable Development of the Russian Society. The Collection of Abstracts of the Third All-Russian Sociological Congress, M.

Makarova, S. N. (2007). Occupational Socialization of the University Students: the Main Approaches to Studying the Periodization. Proceeding of the International Research-to-Practice Conference on "The 
Urgent Social and Psychological Issues of the Personal Enhancement in the Educational Space of the XXI Century", Kislovodsk: Tutor Publishing.

Mead, G. (2007). Mind, Self and Society. M.: Directmedia Publishing.

Morozova, A. V. (2004). Occupational Socialization of the Secondary Specialized College Students in the Context of Modernizing the Education Institutions (PhD Thesis). Tula.

Oparina, O. D. (October 17, 2008). The University Library and Occupational Socialization of a Person. IUBNT Electronic Library Portal. Retrieved October 17, 2008, from http://www.elib.mubint.ru/bio/2006/materials/ files/oparinaod/

Panchenko, O. L. (2005). Occupational Employment of the Young Higher Education Specialists in the Today's Society as a Social Problem: Adapted from the Tatarstan Republic (PhD Thesis). Kazan.

Parsons, T. (1998). The System of Modern Societies. M.: Aspect Press.

Parsons, T. (2000). The Structure of Social Action. M.: Academic Project.

Polishuk V. N. (2013). Problems of professional socialization of youth: Sociological aspect. The Postgraduate bulletin of the Volga region, 7-8, 143-147.

Probst, L. E. (2004). Occupational Socialization of the School Youth in Modern Russia (PhD Thesis). Yekaterinburg.

Professional socialisation of graduates of pedagogical high schools on the basis of use of modern technologies of network interaction [Text]: The collective monography / The collective monography V.V. Sadirin, N.O. Yakovleva, L.V. Trubaychuk, Z.I. Tumaseva [et al.]; under the common edition V.V. Sadirin. - Cheliabinsk: Publishment of Naberegniye Chelni State Pedagogical University, 2013. - 294 p.

Safin, V. F. (1985). The Issues of Personal Identity and Its Activity: Interuniversity Collection of Scientific Papers. Ufa: the Bashkir Teacher Training Institute.

Shtalova, N. I., \& Gemanova, Y. N. (2013). Mechanisms of professional socialization of personality. Weed thematic magazine of scientific publications «Discussion», 1(31).

Smirnova, E. E. (2008, May 12). The Quality of Sociologists' Training: the Employers' View. Social Problems. Social Problems Journal Portal. Retrieved May 12, 2009, from http://www.socprob.ru/index.ru.php/

Sokolov, M. M. (2009). Russian Sociologists in the International and National Idea Market (Scientometric Analysis). Sociological Studies, 1, 144-152.

Spiridonova, G. (1996). The Shift in the System of Young Professionals. Economic Issues, 7, 32.

Stenina T. L. (2014). Professional socialization of students youth of Russia. Knowledge, Understanding, Skills, 3 , $38-47$.

Tartakovskaya, I. (1997). A Sociologist's Life and Career. The Volga Regional Seminar "A Sociologist's Life: Education, Practice and Career". The Region RPC Portal. Retrieved August 2, 2010, from http://www.region.ulsu.ru/books/drugoe_pole/appendix 2/

Toshchenko, J. T. (2008). How to Teach a Sociologist and How to Get Started. Sociological Studies, 7, 1-18.

Valeyeva, A. V. (2007). Occupational Socialization of the Modern Russian Students at the Technical Universities (in the Case of the City of Kazan) ( $\mathrm{PhD}$ Thesis). Kazan.

Weber, M. (1990). The Selected Works. M.: Progress Publishers.

Yadov, V. A. (1999). Theoretical Sociology in Russia: Problems and Solutions. Economy and Society, 3-4, 320.

Zaslavskaya, T. I. (1991). The Sociology of Economic Life: Outline of the Theory. Novosibirsk: Nauka Publishers. Siberian Office.

\section{Copyrights}

Copyright for this article is retained by the author(s), with first publication rights granted to the journal.

This is an open-access article distributed under the terms and conditions of the Creative Commons Attribution license (http://creativecommons.org/licenses/by/3.0/). 